\title{
Results of resection for bronchogenic carcinoma in patients over the age of 80
}

\author{
T SHIRAKUSA, M TSUTSUI, N IRIKI, K MATSUBA, T SAITO, S MINODA, \\ T IWASAKI，N HIROTA, J KUONO
}

From the Lung Cancer Study Group, Kyushu, Japan

ABSTRACT Thirty three patients aged over 80 years underwent resection for bronchogenic carcinoma. The operations performed were: lobectomy (21), segmentectomy (4), wedge resection (2), pneumonectomy (3), carinal resection (1). In two patients no resection was feasible. Three patients died within two months of surgery. The cumulative five year survival rate was $55 \%, 79 \%$ for patients with stage I carcinoma and $31 \%$ for stage III. It is considered that resection has an acceptable outcome in patients over 80 years.

\section{Introduction}

With increased longevity, the number of elderly patients with bronchogenic carcinoma continues to rise. As a result of recent advances in preoperative care and improvement in surgical techniques pulmonary resection can now be performed safely in the elderly, and results of resection for lung cancer for patients over 70 years old are similar to those in younger patients. ${ }^{1-5}$ In Japan the report of the Ministry of Health and Welfare ${ }^{6}$ showed an average life expectancy at age 80 in 1984 of 6.5 years for men and 7.9 years for women. Because surgery is the only effective treatment for lung cancer we have carried it out whenever feasible. Few reports ${ }^{78}$ are available on the results of resection in patients over 80 years.

\section{Patients and methods}

During the years $1978-87,33$ patients (26 of them men) aged over 80 years with primary lung carcinoma underwent thoracotomy in our units. Ninety per cent of the patients were aged 80-5 (mean 82) years; the eldest was 92. Histological specimens were obtained by fibreoptic bronchoscopy and clinical TNM (extent of tumour, state of lymph nodes, presence or absence of metastases) staging routinely included contrast enhanced computed tomography of the thorax. Mediastinoscopic staging was carried out in only one case. Extrathoracic staging included bone and liver

Address for reprint requests: Dr Takayuki Shirakusa, Second Department of Surgery, School of Medicine, Fukuoka University, 45-1, Nanakuma, Fukuoka, 814-01, Japan.

Accepted 13 December 1988 isotope scanning, abdominal ultrasonography, and brain computed tomography in all patients. At operation lymph node dissection was performed in all cases. The staging pathological TNM staging and assessment of resectability were based on the UICC TNM classification' and the general rules for the clinical and pathological reporting of lung cancer of the Japan Lung Cancer Society. ${ }^{10}$

\section{Results}

The operations performed included 21 lobectomies, four segmentectomies, three pneumonectomies, two partial resections, and one carinal resection; resection was not feasible in two patients. Mean preoperative lung function indices are shown in table 1 . Seventeen of the patients had an $\mathrm{FEV}_{1}$ less than $70 \%$ of the predicted value; only one patient had a vital capacity less than $50 \%$ predicted. Mild or moderate hypertension was present in 12 patients, an abnormal electrocardiogram in 15 , and chronic obstructive airways disease in 13, although this was not considered severe enough to be a contraindication to surgery. A pacemaker was inserted before surgery in one patient. Sixteen of the 33 patients had adenocarcinoma, 12

Table 1 Mean (SD) preoperative lung function values in the 33 patients

\begin{tabular}{|c|c|c|c|c|c|}
\hline \multicolumn{2}{|l|}{$F E V_{1}$} & \multicolumn{2}{|l|}{ FVC } & \multirow{2}{*}{$\begin{array}{l}\mathrm{PaO}_{2} \\
(\mathrm{kPa})\end{array}$} & \multirow{2}{*}{$\begin{array}{l}\mathrm{PaCO}_{2} \\
(\mathrm{kPa})\end{array}$} \\
\hline (l) & (\% pred) & (l) & (\% pred) & & \\
\hline $1.63(0.54)$ & $66.4(11.8)$ & $2.46(0.71)$ & $91 \cdot 2(21 \cdot 2)$ & $10 \cdot 7(1 \cdot 2)$ & $4.9(0.7)$ \\
\hline
\end{tabular}


Table 2 Postoperative complications in the 33 patients

\begin{tabular}{lll}
\hline & $\begin{array}{l}\text { No of } \\
\text { patients }\end{array}$ & $\begin{array}{l}\text { No of deaths } \\
\text { (postoperative days) }\end{array}$ \\
\hline $\begin{array}{l}\text { Dysrhythmia } \\
\text { Mental disturbance }\end{array}$ & 7 & \\
Prolonged air leakage & 2 & \\
Empyema & 2 & $2(50,57)$ \\
Gastrointestinal bleeding & 2 & $1(40)$ \\
Pulmonary oedema & 1 & $1(33)$ \\
Pneumonia & 1 & \\
Chylothorax & 1 & \\
\hline
\end{tabular}

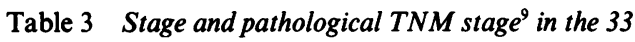
operated patients

\begin{tabular}{lcc}
\hline & & No of patients \\
\hline Stage I & $\left\{\mathrm{T}_{1} \mathbf{N}_{0} \mathbf{M}_{0}\right.$ & 7 \\
Stage II & $\mathbf{T}_{2} \mathbf{N}_{0} \mathbf{M}_{0}$ & 11 \\
Stage III & $\mathbf{T}_{2} \mathbf{M}_{0} \mathbf{M}_{0}$ & 1 \\
$\mathbf{T}_{3} \mathbf{N}_{0} \mathbf{M}_{0}$ & 4 \\
$\mathbf{T}_{3} \mathbf{N}_{1} \mathbf{M}_{0}$ & 6 \\
$\mathbf{T}_{3} \mathbf{N}_{2} \mathbf{M}_{0}$ & 1 \\
$\mathbf{T}_{2} \mathbf{N}_{0} \mathbf{M}_{1}$ & 2 \\
\hline
\end{tabular}

T-tumour; N-lymph nodes; M-metastases.

squamous carcinoma, three anaplastic carcinoma, and two adenosquamous cell carcinoma.

Surgical complications developed in 16 patients and are summarised in table 2 . No patient died within a month of surgery but four died within two months, from empyema, gastrointestinal bleeding, and pul-

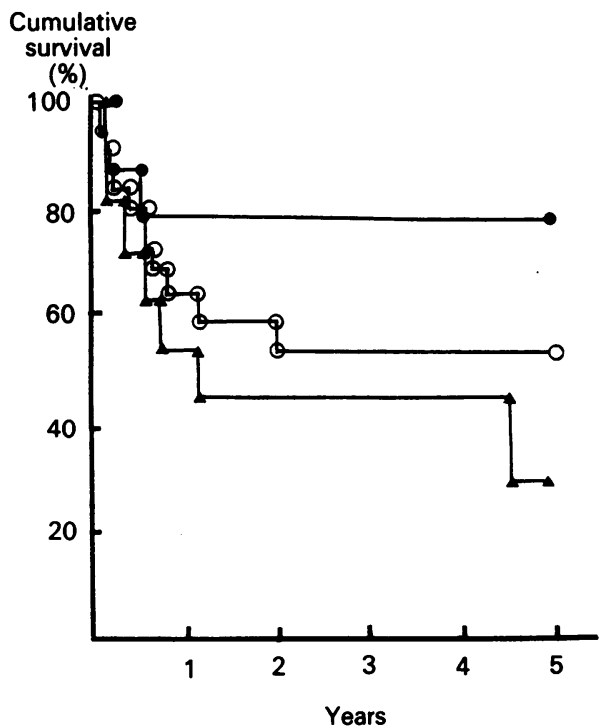

Fig 1 Cumulative five year survival in patients over the age of 80 with stage I (O) and stage III ( $\Delta$ ) disease and for all patients $(O)$ who underwent surgery for lung carcinoma (stage I v stage III: $p<0.05$ ).

\section{Cumulative}

survival

(\%)

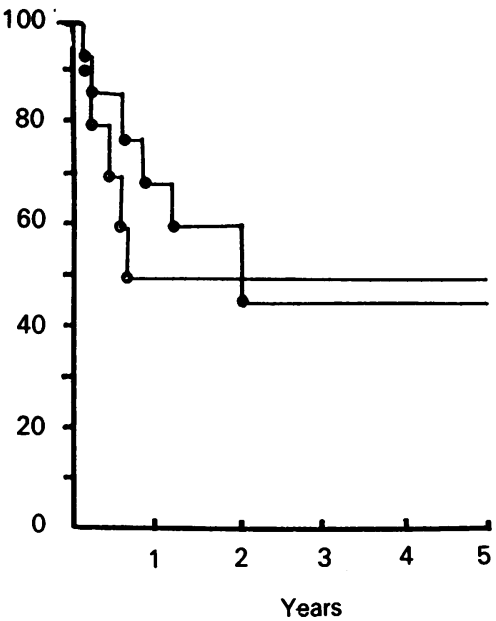

Fig 2 Cumulative five year survival in patients over the age of 80 with squamous carcinoma $(O)$ and adenocarcinoma

(O) who underwent surgery for lung carcinoma (no significant difference between the groups).

monary oedema respectively. The patient with pul $\overrightarrow{\overrightarrow{0}}$ monary oedema was a 92 year old man who had had a myocardial infarction in the second postoperative week. The postsurgical (pathological) TNM classifications are shown in table 3. Eighteen patients had stage I disease and 13 stage III. One patient had stage IV? disease because a brain metastasis was found soon $x$ after the lung resection. The cumulative five yeas survival for all patients was $55 \%$ (fig 1). Stage $\vec{b}$ patients had a five year survival rate of $79 \%$ and stage III patients $31 \%$ (stage I $v$ stage III: $\mathrm{p}<0.05$ ). There was one early death in stage I patients and two in the stage III group. The cumulative five year survival rate was $50 \%$ for patients with squamous carcinoma and $\mathbf{4 4 \%}$ for those with adenocarcinoma $44 \%$ (fig 2 ).

\section{Discussion}

The incidence of bronchogenic carcinoma is increasing and the results of resection in patients aged over 70 are acceptable. ${ }^{1-2}$ In patients over 80 , however, resection? is unusual, and there is scanty information on the prognosis for such patients. ${ }^{78}$ Opinions differ on the influence of age. Higgins and Beebe ${ }^{8}$ emphasised tha survival after surgery is strongly influenced in aD negative fashion by increasing age, but others have refuted this. Breyer et al insisted that no patient 
should be denied thoracotomy because of age. In the study of Kirsh et al $^{3}$ the absolute five year survival rate for the 55 patients over 70 was $30 \%$ and similar results in 81 patients over 70 were reported by Evans. ${ }^{4}$ In our series the cumulative five year survival rate was $55 \%$, confirming that age was unrelated to survival. Our encouraging results may largely reflect the fact that most patients had stage I disease and good lung function.

Reports on the outcome of thoracotomy in elderly patients in the 1970s indicated a death rate of $15-20 \%$ after surgery, whereas in the 1980s the rate has been regularly reported as less than $6 \%$. Breyer et al described a surgical mortality of $4 \%$ in 150 patients over 70 years old. Ginsberg et al ${ }^{11}$ analysed the surgical mortality rate of the various participating centres in the Lung Cancer Study Group in the United States and Canada from 1979 to 1981 . Mortality was $7 \%$ over the age of $70,4 \%$ at $60-69$ years, and $1 \%$ under 60 years. In our own experience of 103 resections in patients of 70-79 years over 10 years six patients died within a month of surgery. In the present series there was no death within one month of surgery but three patients died one to two months after surgery. We agree with Berggren et al ${ }^{12}$ that mortality is not correlated with age.

Postoperative cardiopulmonary complications are frequent, especially dysrhythmias. ${ }^{13}$ Ohata ${ }^{7}$ found that the most common cause of early postoperative death in patients over 80 years with lung carcinoma, other than the cancer itself, was pneumonia.

We conclude that the decision on whether to resect lung cancer in a patient over 80 should be based not on the patient's age but on the extent of the disease and the patient's cardiovascular and pulmonary reserve.

\section{References}

1 Breyer RH, Zippe C, Pharr WF, Jensik RJ, Kittle CF, Faber LC. Thoracotomy in patients over age seventy years. J Thorac Cardiovasc Surg 1981;81:187-93.

2 Yellin A, Benfield JR. Surgery for bronchogenic carcinoma in the elderly. Am Rev Respir Dis 1985;131:197.

3 Kirsh MM, Rotman H, Bove E, et al. Major pulmonary resection for bronchogenic carcinoma in the elderly. Ann Thorac Surg 1976;22:369-73.

4 Evans EWT. Resection for bronchial carcinoma in the elderly. Thorax 1973;28:86-8.

5 Harriel DJ, McNamara JJ, Straehly CJ. Surgical treatment of lung cancer in patients over the age of 70 years. J Thorac Cardiovasc Surg 1978;75:802-5.

6 Statistics and Information Department, Ministry of Health and Welfare, Japan. The abridged life table for Japan 1986:33:102.

7 Ohata M, Surgical treatment of lung tumor in patients over 80 years of age [in Japanese]. Nihon Kyobu Rinsho 1983:42:275-82.

8 Higgins G, Beebe G. Bronchogenic carcinoma: factors in survival. Arch Surg 1976;94:539-49.

9 UICC. TNM, Classification of malignant tumors. Berlin: Springer, 1987.

10 Japan Lung Cancer Society. General rule for clinical and pathological reporting of lung cancer [in Japanese]. 3rd ed. Tokyo: Kanehara, 1987.

11 Ginsberg RJ, Hill LD, Eagen RT. Modern thirty-day operative mortality for surgical resection in lung cancer. $J$ Thorac Cardiovasc Surg 1983;86:654-8.

12 Berggren H, Ekroth R, Malmberg R, Naucler J, WilliamOlsson G. Hospital mortality and long-term survival in relation to preoperative function in elderly patients with bronchogenic carcinoma. Ann Thorac Surg 1984:38:633-6.

13 Nagasaki F, Flehinger BJ, Martini N. Complications of surgery in the treatment of carcinoma of the lung. Chest 1982;82:25-9. 